\title{
Optimal Maximum Speed during Off-Peak Hours for Reduced Energy Consumption of the Bangkok MRT
}

\author{
Guntinan SAKULPHAISAN and Boonruang MARUNGSRI* \\ School of Electrical Engineering, Suranaree University of Technology, Thailand \\ ${ }^{*}$ Corresponding author
}

\begin{abstract}
Nowadays, energy management is an essential strategy for reducing the energy cost in the metro system. This paper discusses the energy efficiency management by control the speed of metro for reducing the energy consumption during the off-peak period of the Chalerm Ratchamongkol metro line or the Bangkok MRT. The control conditions included the average speed throughout the route is not lower than $40 \mathrm{~km} / \mathrm{hr}$. and the trip time must be less than 5 minutes. The optimal maximum speed was determined by using Particle Swarm Optimization Technique (PSO). The simulation result showed that the energy consumption after changing the maximum speed to the optimal value reduced $u$ p to $20.89 \mathrm{kWh}$ per trip.
\end{abstract}

Keywords-energy consumption; optimal maximum speed; particle swarm optimization; energy management strategy

\section{INTRODUCTION}

Presently, Bangkok MRT Organization is the metro service in Bangkok consists of 18 stations having total distance $19.5 \mathrm{~km}$. The Bangkok MRT services 19 hours per day consists of 12 hours during off-peak hours and 7 hours for peak-hours. The metro network is called Chalerm Ratchamongkol line that separates into two sections. The first section is a north section which the route of the north section start at Bang sue station and the end at Thailand Cultural Center station. The second section is a south section which starts at Pha Ram IX station to Hua Lumpong station. The route of Bangkok MRT is shown in Figure I.

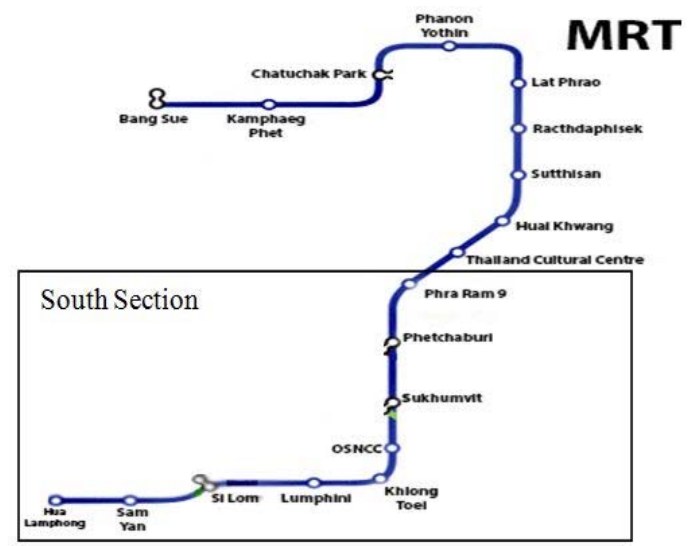

FIGURE I. THE CHALERM RATCHAMONGKOL LINE OR THE BANGKOK MRT
Various methods were used to reduce the energy consumption of metro network. Installation of energy storage system to store braking energy during the braking period is one of the methods for this proposed. Also, designing the metro with the low weight of material or design the shape of metro for reducing rolling force is adopted. Furthermore, the optimal timetable provides optimal energy consumption during the service period. The last method is the optimal metro speed for reducing energy consumption during off-peak hours.

To find the best solution, many researchers studied this problem. Fan et al. (2015) introduced the two important components of speed profile and tracking strategy to analyze energy consumption by using Ant Colony Algorithm. Their result showed that the optimal speed profile could save usage energy consumption up to $8.64 \%[1]$. Aradi, Becsi, and Gaspar (2013) introduced the predictive optimization method for a train speed profile. Their goal was to generate a speed profile which the highest efficiency of energy consumption by using an algorithm approach both traveling time and energy consumption. By using their optimization method, the result showed that the energy consumption reduced from $79.5 \mathrm{kWh}$ to $67.3 \mathrm{kWh}[2]$. Hamid et al. (2016) investigated the train positioning systems for saving energy with optimized train trajectories. They reduced the metro speed which has a significant effect on the traction energy consumption because the reduction of speed can reduce running resistance force of the metro[3]. Ahmadi and Dastfan (2016) obtained the energy consumption-time by using the non-dominated sorting algorithm. They used the speed profile optimization with two objective functions of net energy and the traveling time interstation distance. Their result showed the relation of the rate of regenerative energy, energy consumption saving, and operational management[4]. Ghaviha, Bohlin, and Dahlquist (2016) studied the speed profile optimization of an electric train with onboard energy storage and continuous tractive effort. They developed the algorithm for speed profile optimization with onboard energy storage device which metro model. The objective function was based on the equation of motion[5]. Martinis and Gallo (2013) introduced models and methods to optimize train speed profiles with and without Energy Recovery Systems. Their primary energy consumption model was based on operation energy requirement by traction unit and the energy requirement for the auxiliary system[6]. Mahamad(2016) developed the particle swarm optimization code for Matlab Program that uses to find a minimum value of problem[7]. 


\section{Characteristic OF THE MEtro}

The energy using in traction system of metro consists of traction energy and loss energy of traction substation. The energy consumption of metro depends on traction effort, which varies speed, accelerates, the slope of the railway and running resistance. Speed profile of the subway was separated into four



(a) modes include accelerating mode, cruising mode, coasting mode and braking mode, as shown in Figure. II (a). In this case, the travel distances between stations are a short distance. Therefore, the speed profile was divided into three modes include accelerating mode, cruising mode, and braking mode, as shown in Figure. II (b).

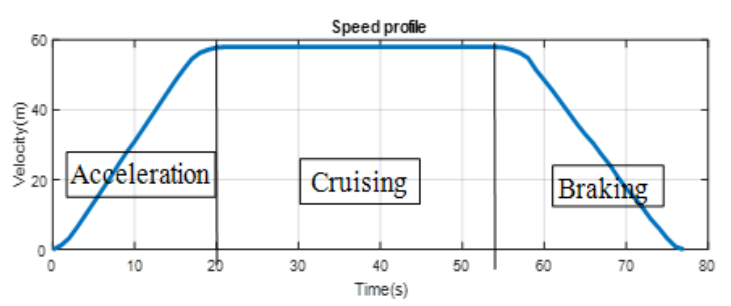

(b)

FIGURE II. (A) THE GENERAL SPEED PROFILE AND (B) THE SIMULATION SPEED PROFILE

The problem of the metro system isn't installs energy storage device that causes regenerative braking energy can't store. Therefore, the total regenerative braking energy was converted to heat energy. The calculation of energy consumption in this paper based on energy consumption model which explained the energy required for metro running along a track with motion parameters could be expressed as the integral of the mechanical power over time. The mechanical power is the power measured at the wheel-rail interface and can be computed as the product of the traction effort, and speed the equation (1) is the of energy consumption model. When $F(v, t)$ is traction effort, $v$ is speed and $\mathrm{E}$ is energy consumption

$$
E=\int_{t \in T} P_{\text {mech }}(t) d t=\int_{i \in T} v \cdot F(v, t) d t
$$

\section{MECHANICAL MODEL}

The aims of this section to introduce the mathematic equations of the metro model and factors affecting the energy consumption.

\section{A. Metro Model}

The metro is considered as the single mass model. The characteristic of traction effort is based on the 2nd force law of Newton. Total acting forces expressed in equation (2).

$$
\sum F=F_{t}-F_{R R}-F_{G}
$$

Where $F_{t}, F_{R R}, F_{G}$ are traction effort, rolling force, gradient force or slope force, respectively.

\section{B. Rolling Force $\left(F_{R R}\right)$}

Rolling resistance is the resistance to movement of the metro. It is a fictional torque. The manufacturer usually determined the rolling force with the aerodynamic drag force. The result of rolling force and aerodynamic drag force are proposed in Davis equation. The Davis equation is shown in equation (3).

$$
F_{R R}=a+b v+c v^{2}
$$

Where a, b, c are Davis Coefficient and v is the velocity of the metro.

\section{Gradient Force $\left(F_{G}\right)$}

Gradient force is a resistance force that occurs when the metro moves uphill, downhill or move through different levels. The gradient force equation was shown in equation (4)

$$
F_{G}= \pm M_{e f f} g \sin \theta
$$

When $M_{\text {eff }}$ is effective mass and $\theta$ is the angle of slope. Equation (2), (3) and (4) can apply to the equation for movement mode of the metro. The movement modes of the metro are separated into three modes. The equation of each mode is shown in next section.

\section{Accelerating Mode}

In this mode the equation of traction effort is

$$
F_{t}=M \times a+F_{R R}+F_{G}
$$

The energy consumption in this accelerating mode for prepare velocity of the metro to cruising mode can calculate from equation (6)

$$
E_{a c c}=M \times \frac{v_{i+1}^{2}+v_{i}^{2}}{2}+F_{R R} \times S^{a c c}+F_{G} \times S^{a c c}
$$




\section{E. Cruising Mode}

In this part speed of metro is a constant value and traction effort equal total rolling resistance. The energy consumption for the metro at cruising mode is shown in equation (7).

$$
E_{\text {cruis }}=F_{R R} \times S^{\text {cruis }}+F_{G} \times S^{\text {cruis }}
$$

\section{F. Braking Mode}

In this part braking effort was fed to traction system for resist train movement. In general, during braking period kinematic energy is negative due to accelerate value in this mode in negative. The negative kinematic energy is affected by the slope of speed profile. Energy consumption during the braking period was shown in equation (8)

$$
E_{\text {brake }}=-M \times \frac{v_{i+1}^{2}+v_{i}^{2}}{2}+F_{R R} \times S^{\text {brake }}+F_{G} \times S^{\text {brake }}
$$

\section{G. Trip Time for Each Mode Calculation}

Trip time of metro after change velocity is an essential condition to find optimal speed. So that trip time equation of journey separated into three modes is time for accelerating mode, time for cruising mode and time for braking mode. The equations for each mode are shown in equation (9), (10),(11) and (12), respectively

$$
\begin{gathered}
T_{\text {trip }}=T_{\text {acc }}+T_{\text {cruis }}+T_{\text {braking }} \\
T_{\text {acc }}=\frac{v(i)}{a} \\
T_{\text {cruis }}=\frac{v(i+1)-v(i)}{a} \\
T_{\text {brake }}=\frac{v(i)}{\beta}
\end{gathered}
$$

\section{OPTIMIZATION MODEL}

The route of metro each station consists of three modes which discussed at section 2. Assume acceleration rate and deceleration rate are a maximum value for the metro runs with safety. First, the metro departs from station A with accelerating mode after velocity of train reach optimal maximum speed; The metro must change from accelerating mode to cruising mode for keeping the speed constant. After that before arrival station B the metro have to switch from cruising mode to braking mode for reducing the speed of metro. After that, the optimal maximum speeds for reducing the energy consumption of metro need the equation (6), (7) and (8). Therefore the objective function of optimal speed for minimum energy consumption is shown in equation (13).

$$
\min E=\sum E_{\text {acc }}+E_{\text {cruis }}+E_{\text {brake }}
$$

The conditions for determining the area of the objective function are shown in equations (14), (15) and (16). Respectively.

$$
0<v_{i}<80
$$

$$
\begin{gathered}
40>\frac{\sum_{i=0}^{N} v_{i}}{N} \\
T_{\text {trip }}<600
\end{gathered}
$$

\section{Simulation RESUlts}

This paper selected a southern section of the Bangkok MRT or Chehalem Ratchamongkol line for study the optimal maximum speed of the metro. The study case start at Hua Lumpong station and end at Pha Ram IX station. The Bangkok MRT is a DC-fed line with six traction substations. The simulations considered only the case of one-train moves along the track. The optimization criterion was verified by using the PSO technique. The parameters of the Bangkok MRT are shown in Table I Details of the routes are shown in Table II. The track elevation is shown in Figure III.

TABLE I. PARAMETERS OF THE BANGKOK MRT

\begin{tabular}{|c|c|c|c|}
\hline Parameter & Value & Parameter & Value \\
\hline $\begin{array}{c}\text { Tare } \\
\text { weight }\end{array}$ & 107.1 Ton & $\begin{array}{c}\text { Maximum } \\
\text { speed }\end{array}$ & $\begin{array}{c}80 \\
\mathrm{~km} / \mathrm{hr}\end{array}$ \\
\hline Payload & $53.2 \mathrm{Ton}$ & Accelerate & $1.3 \mathrm{~m} / \mathrm{s}^{2}$ \\
\hline $\begin{array}{c}\text { Rolling } \\
\text { resistance }\end{array}$ & $3,520+30.56 \mathrm{v}+2.28 \mathrm{v}^{2}$ & Decelerate & $0.9 \mathrm{~m} / \mathrm{s}^{2}$ \\
\hline
\end{tabular}


TABLE II. ROUTE OF THE BANGKOK MRT

\begin{tabular}{|c|c|c|c|c|c|}
\hline Departure & Arrival & $\begin{array}{c}\text { Distance } \\
\text { (m) }\end{array}$ & $\begin{array}{l}\text { Trip time } \\
\text { (s) }\end{array}$ & $\begin{array}{c}\text { Maximum } \\
\text { Speed } \\
(\mathrm{km} / \mathrm{hr})\end{array}$ & $\begin{array}{c}\text { Energy } \\
\text { Consumed } \\
(\mathrm{kWh})\end{array}$ \\
\hline Hua Lumpong & Samyan & 1,496 & 90.7 & 80 & 23.60 \\
\hline Si lom & Lumphini & 983 & 68.0 & 80 & 20.05 \\
\hline Lumphini & Bonkai & 985 & 67.4 & 80 & 17.12 \\
\hline Bonkai & Queen Sirikit & 809 & 64.3 & 80 & 18.07 \\
\hline Sukhumvit & Phetchaburi & 1306 & 81.8 & 80 & 21.00 \\
\hline Phetchaburi & Pha Ram IX & 926 & 64.8 & 80 & 19.75 \\
\hline & -12 & Track Elev & 8 & 10 & \\
\hline
\end{tabular}

FIGURE III. THE TRACK ELEVATION

TABLE III. THE SIMULATION RESULT OF ENERGY CONSUMED, TRIP TIME AND MAXIMUM SPEED

\begin{tabular}{|c|c|c|c|c|}
\hline Departure & Arrival & $\begin{array}{c}\text { Trip time } \\
(\mathrm{s})\end{array}$ & Maximum speed $(\mathrm{km} / \mathrm{hr})$ & Energy consumed(kWh) \\
\hline Hua Lumpong & Samyan & 162 & 66 & 20.50 \\
\hline Samyan & Si Lom & 156 & 64 & 13.94 \\
\hline Si lom & Lumphini & 117 & 60 & 18.22 \\
\hline Lumphini & Bonkai & 108 & 63 & 14.97 \\
\hline Bonkai & Queen Sirikit & 91 & 64 & 14.70 \\
\hline Queen Sirikit & Sukhumvit & 229 & 53 & 22.00 \\
\hline Sukhumvit & Phetchaburi & 156 & 60 & 19.48 \\
\hline Phetchaburi & Pha Ram IX & 103 & 65 & 17.02 \\
\hline
\end{tabular}

The optimal speed for reducing the energy consumption of the Bangkok MRT was obtained from the simulation result. Reduced the maximum speed from $80 \mathrm{~km} / \mathrm{hr}$ to optimal speed for each trip obtained the energy saving up to $4.54 \mathrm{kWh}$ per trip or $20.89 \mathrm{kWh}$ per throughout route. Decreasing the maximum speed effects the increasing of trip time. However, the trip time of the Bangkok MRT is still following the standard even reducing the maximum speed.

\section{CONCLUSION}

The optimal maximum speed to minimize the energy consumption for the Chalerm Ratchamongkul metro network or the Bangkok MRT was proposed in this paper. The proposed method based on an energy consumption model. The energy consumption model required parameters from the mechanical model for creating an objective function and the condition equation of each case. The mechanical model is a part of energy consumption model consists of a metro model, rolling force and gradient force used to calculate a traction effort of the metro. Therefore the result of optimal maximum speed for given minimum energy consumption depends on traction effort, distance and speed. The results showed that the energy consumption after the adjusted maximum speed of the metro to an optimal value by using PSO technique via Matlab program.

\section{REFERENCES}

[1] Fan, L., Cao, F., Ke, B., \& Tang, T. Speed profile optimization for train operation based on ant colony algorithm. 2015 IEEE Advanced Information Technology, Electronic and Automation Control Conference (2015).

[2] Aradi, S., Becsi, T., \& Gaspar, P. A predictive optimization method for energy-optimal speed profile generation for trains.2013 IEEE 14th International Symposium on Computational Intelligence and Informatics (2013).

[3] Hamid, H. A., Nicholson, G. L., Douglas, H., Zhao, N., \& Roberts, C. The investigation into train positioning systems for saving energy with optimised train trajectories.2016 IEEE International Conference on Intelligent Rail Transportation (2016).

[4] Ahmadi, S., \& Dastfan, A. Energy saving in urban railway using speed profile optimization. 2016 24th Iranian Conference on Electrical Engineering (2016).

[5] Ghaviha, N., Bohlin, M., \& Dahlquist, E. Speed profile optimization of an electric train with onboard energy storage and continuous tractive effort.2016 International Symposium on Power Electronics, Electrical Drives, Automation and Motion (2016).

[6] Martinis, V. D., \& Gallo, M. (2013). Models and Methods to Optimise Train Speed Profiles with and without Energy Recovery Systems: A Suburban Test Case.Procedia - Social and Behavioral Sciences,(2013).

[7] Information on https://www.researchgate.net/publication/296636431_Codes_in_MATL AB_for_Particle_Swarm_Optimization. 